Goran Cukor

Graciela Šterpin-Valić

Tihana Kostadin

Marko Fabić

https://doi.org/10.21278/TOF.43301

ISSN 1333-1124

eISSN 1849-1391

\title{
SUSTAINABLE TURNING OF MARTENSITIC STAINLESS STEEL
}

\begin{abstract}
Summary
The development of ecological awareness followed by stringent laws on the protection of natural resources and workers direct the manufacturing industry at the development and implementation of alternative methods for cooling and/or lubrication in the machining of metals. The paper investigates the feasibility of using a vortex tube for cooling when turning martensitic stainless steel. Experimental research was conducted to understand the effects of vortex tube cooling on the corrosion resistance of the machined surface and on production costs. It has been determined that the vortex tube cooling has no significant influence on the corrosion resistance and that the tool costs have the most significant influence on the unit production cost. In conclusion, compared to the conventional emulsion cooling in metal cutting, the vortex tube cooling offers a cost-effective solution to the sustainable turning of martensitic stainless steel.
\end{abstract}

Key words: $\quad$ sustainable turning, cooling, vortex tube, martensitic stainless steel

\section{Introduction}

At the beginning of the 1960s, scientists began to show concern for the adverse impact of cutting fluids on the environment and humans. Mortier et al. [1] drew attention to the disturbing fact that only $32 \%$ of the total amount of these fluids used in the European Union are disposed of after use in an environmentally sound manner.

"Environmentally friendly" or "sustainable" or "green" manufacturing are synonyms for a modern production strategy with the goal of reducing pollution and waste during the life of a product. To achieve that goal, sustainable manufacturing focuses on cutting fluids which are among major pollutants. Various approaches are available to reduce the environmental load imposed by conventional wet machining: changes in the composition of cutting fluids, use of a minimum quantity of cutting fluids, cryogenic machining, cooling with chilled compressed air, and dry machining.

Brinksmeier et al. [2] provided a comprehensive overview of cutting fluids with special emphasis on their properties and development regarding their ecological characteristics. The 
authors also dealt with the use of alternative methods for cooling and/or lubrication in machining. The use of naturally biodegradable vegetable oils or synthetic esters is greatly encouraged instead that of mineral oils. Liao et al. [3] found that the application of minimum quantity lubrication (MQL technique) to the high-speed end milling of hardened steel gives better results of the machined surface roughness compared to conventional wet machining. Ezugwu [4] presented the results of hard milling of difficult-to-cut aerospace superalloys, which show a significantly longer tool life when using a cryogenic fluid instead of a conventional one. Boswell [5] confirmed that the cooling effect of chilled compressed air generated by a vortex tube is closely comparable to that of a cutting fluid. Weinert et al. [6] investigated the advantages of dry machining over wet machining; among them, they emphasized savings and the growth of corporate image when cutting fluids are not used. However, Klocke [7] pointed out that a possibility of dry machining application depends heavily on the machining operation and the workpiece material. Generally, compared to the cutting fluids, alternative cooling and/or lubrication methods give a better machining effect under certain conditions. Environmental, health, and economic aspects should be added to the advantages of the alternative cooling and/or lubrication methods.

Martensitic stainless steels, as well as other groups of stainless steels, ensure a long product life with low maintenance and can be fully recycled when the product is discarded. Owing to the low thermal conductivity of these steels, high-flow cutting fluids should be used during machining and all liquid traces should be removed in the post-processing stage to allow self-passivation of the machined surface. Considering the negative impacts arising from the use of conventional cutting fluids, the aim of this study is to introduce an alternative cooling method using a vortex tube in the turning of martensitic stainless steel. This method contributes to the protection of the environment and workers' health and to a reduction in machining costs.

\section{Ecological, health, and economic aspects of cutting fluids}

The primary tasks of a cutting fluid are the cooling and lubrication of the tool and workpiece in the cutting zone, and the flushing of the chips and particles resulting from the tool wear [8]. Cooling dissipates the generated heat and lubrication reduces the friction of the cutting edge. This reduces the cutting force, and thus the machining power needed, and the tribological processes such as tool wear are slowed down. Apart from the increase in tool life, the machined surface quality is improved, the costs of a possible subsequent machining operation decrease, and the machining productivity increases.

In the classification of cutting fluids, cutting oils have primarily lubricating properties and water-miscible fluids (emulsions, semi-synthetic and synthetic fluids) have primarily cooling properties. Cutting oils can be mineral, vegetable, animal, and synthetic, or can be mixtures; they are used at low-speed machining without a significant temperature rise to reduce adhesion and abrasion. Emulsions are fluids based on mineral oils dispersed in water; they contain emulsifiers that maintain the oil in fine droplets, corrosion inhibitors, and, if necessary, other additives to improve the working properties; they are used in machining at higher cutting speeds where there is a larger temperature rise. Semi-synthetics are microemulsions that contain a very small amount of mineral oil dispersed in water. Synthetics are aqueous solutions based on synthetic (chemical) components with additives, which do not contain any oil. 
The application of cutting fluids raises numerous ecological questions. When losses of cutting fluids through evaporation, uncontrolled leakage and residual quantities at the workpiece, tool or chips are concerned, it follows that almost $30 \%$ of the total annual consumption of cutting fluids comes out from the machining system into the environment [9]. A special problem is the disposal of waste cutting fluids. They are classified as hazardous waste [10] and need to be safely disposed of in a way that does not endanger human health and does not harm the environment [11]. Spillage of waste fluids as well as drainage into sewer or into the rainwater drainage system may contaminate soil, groundwater, rivers, lakes or seas. Proper disposal of cutting fluids implies recycling or burning as fuel.

Handling of cutting fluids poses danger to human health and is a possible cause of various diseases, most commonly the skin diseases caused by a direct contact with them and malignant and non-malignant respiratory diseases. Other hazardous effects are the effect of oil vapours, bactericidal effect, genotoxic effect, generation of carcinogens, presence of heavy metal particles in additives, etc.

It is estimated that around $16 \%$ of the total production costs are caused by costs related to cutting fluids (20-30\% in the machining of difficult-to-cut materials) [12]. This is far more than the costs of tools that account for approximately $2-4 \%$ of the total production costs. The costs attributed to the cutting fluids are not restricted to the procurement and prearrangement, but also include the costs of upkeep and disposal. The costs of disposal of waste cutting fluids can be over four times higher than their procurement price mainly because most of the cutting fluids are not naturally biodegradable, and consequently require expensive treatment [13].

\section{Vortex tube cooling}

Experimental research conducted in $[5,14]$ set out cooling with chilled compressed air as one of the most efficient cooling techniques in the machining of metals. Removal of chips from the cutting zone is also successful. The air used as a cooling medium is completely natural and this cooling technique is the cleanest and most environmentally acceptable [15]. Unlike liquids, the compressed air penetrates more easily the contact surfaces of the tool in the cutting zone. The main disadvantage of air is that there is no lubrication function, but it can be partially overcome by the selection of suitable self-lubricating coatings (typically molybdenum disulphide coatings).

Cooling with chilled compressed air is most often carried out by means of a vortex tube. The first note on the vortex tube was recorded on December 12, 1931, when Georges Joseph Ranque filed a patent in France for his accidental discovery. However, the vortex tube became widely known only in 1946 when a German physicist, Rudolf Hilsch, published an article providing details of the improved design of the vortex tube in. Thus, the vortex tube is also called the Ranque-Hilsch vortex tube.

The vortex tube is a simple device with no moving parts; it separates compressed air into two swirling streams, a hot and a cold one. Figure 1 shows a counter-flow vortex tube. Compressed air is tangentially introduced into the vortex generation chamber through one or more nozzles; it then accelerates to high rotational speeds (up to $10^{6} \mathrm{~s}^{-1}$ ) and is directed down the tube. Because of the centrifugal force, the air moves towards the control valve at the hot end of the tube through its peripheral area. The control valve leaks a small portion of the swirling air stream along the wall of the tube while the remainder is forced to return through the centre area of the tube. On its path, the inner swirling stream of the air transmits the heat to the outer stream and exits with a significant drop in temperature at the tube cold end. The 
cold air stream can reach a temperature of as low as $-50{ }^{\circ} \mathrm{C}$ while the hot air stream can reach $100{ }^{\circ} \mathrm{C}$. There is also a design of the vortex tube with a parallel flow of both air streams, but its efficiency is lower. The phenomenon of airflow separation into two temperature ranges is known as the Ranque-Hilsch effect. Although there are numerous numerical and experimental analyses of this effect, there is still no single physical explanation of the occurrence of radial temperature separation in the vortex tube.

The wide applicability of the vortex tube is based on its simplicity, low investment costs, compactness, low weight, and extremely quiet operation. Since it does not contain any moving parts, the vortex tube does not break nor is subject to wear, which makes it easy to maintain. In addition to cooling the cutting zone, the vortex tube can also be used for cooling the high-speed spindles of CNC machine tools [16]. Compressed air required for its operation can commonly be found in any production plant. It should be noted that due to a high volume of airflow, a large capacity compressor is needed [17].

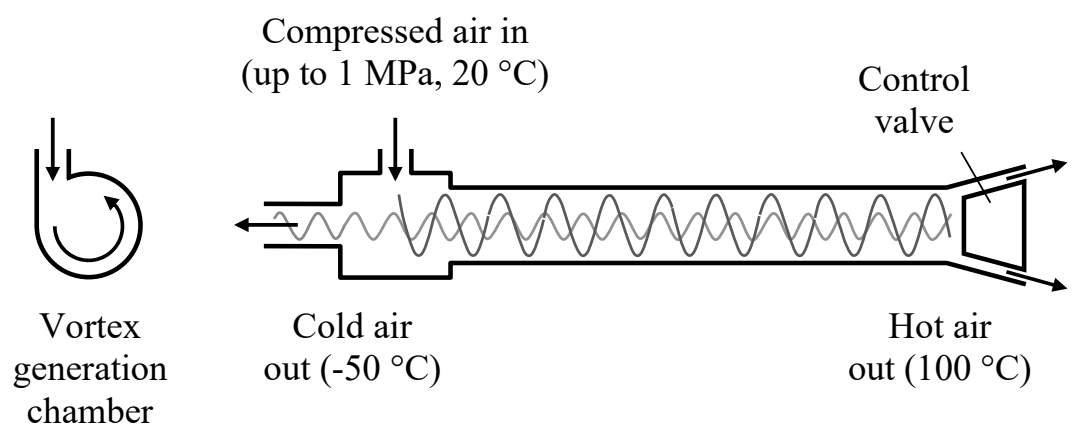

Fig. 1 Counter-flow vortex tube operating principle

\section{Material and the experimental procedure}

The material tested in the experiment was quenched and tempered martensitic stainless steel X20Cr13 (0.236 \% C, $11.97 \%$ Cr, $0.299 \%$ Ni, $0.683 \%$ Mn, $0.352 \%$ Si, $0.125 \%$ Mo, $0.023 \% \mathrm{~S}, 0.044 \% \mathrm{P}, 0.053 \% \mathrm{~V}, 0.07 \% \mathrm{Nb}, 0.195 \% \mathrm{Cu}, 85.85 \% \mathrm{Fe})$. The mechanical properties were as follows: yield strength $R_{p(0.2)}=750 \mathrm{MPa}$, tensile strength $R_{m}=881 \mathrm{MPa}$, and hardness $=272 \mathrm{HB}$.

A $2^{3}$ factorial design experiment with four observations at the centre point was carried out. The cutting parameters used were the cutting speed $v_{c}=170,220$, and $270 \mathrm{~m} / \mathrm{min}$, the feed $f=0.2,0.3$, and $0.4 \mathrm{~mm} /$ revolution, and the depth of cut $a_{p}=0.3,0.4$, and $0.5 \mathrm{~mm}$.

The turning experiments were conducted on the bars with dimensions of $\varnothing 80 \times 463$ mm. An CNC lathe TU 360 Prvomajska, Seco DNMG 150608-MF-4 cutting inserts of TP 2501 grade, and a tool holder PDJNL 2525M15 were used.

For wet machining, $5 \%$ emulsion (INA BU 7 concentrate) at a flow rate of $4.8 \mathrm{l} / \mathrm{min}$ was used. A counter-flow vortex tube produced by Nex Flow ${ }^{\mathrm{TM}}$, labelled Frigid-X Cooler System c/w 57025AD was used for cooling with chilled air; the flow rate of the chilled air at the entrance was $708 \mathrm{l} / \mathrm{min}$ and the air pressure $0.69 \mathrm{MPa}$.

The surface roughness measurements (mean roughness $R a$ ) were made using a Hommel Tester T1000 profilometer. To avoid possible mistakes due to re-clamping operation, the $R a$ values were measured directly on the workpiece in the lathe, Figure 2. Also, to reduce deviation, the average value of three measurements was taken as a result of each experiment. The experimental results of surface roughness were checked by a statistical $F$-test and a $t$-test. 
The tool life $T$ was estimated as stated in the ISO 3685 standard [18] for a flank wear criterion of $V B=0.5 \mathrm{~mm}$. A digital microscope Dino Lite Pro (magnification 230x) was used for measuring the tool wear. Models of the tool life (the extended Taylor equations) were determined by the regression analysis of experimental results.

The machined surfaces and their elemental compositions were obtained applying Scanning Electron Microscopy and Energy Dispersive X-ray Spectroscopy (SEM/EDS technique).

Gravimetric measurements were performed using specimens with a working area of 1 $\mathrm{cm}^{2}$ prepared using the following cutting parameters: $v_{c}=220 \mathrm{~m} / \mathrm{min}, f=0.3 \mathrm{~mm} /$ revolution, and $a_{p}=0.4 \mathrm{~mm}$. The specimens were weighed prior to immersion and after 14 days of immersion in $3.5 \% \mathrm{NaCl}$ aqueous solution at a temperature of $25{ }^{\circ} \mathrm{C}$. Assuming uniform corrosion, the time-averaged corrosion rate $C R_{G}$ in $\mathrm{mm} /$ year was estimated in accordance with the ASTM Standard G1-03 [19].

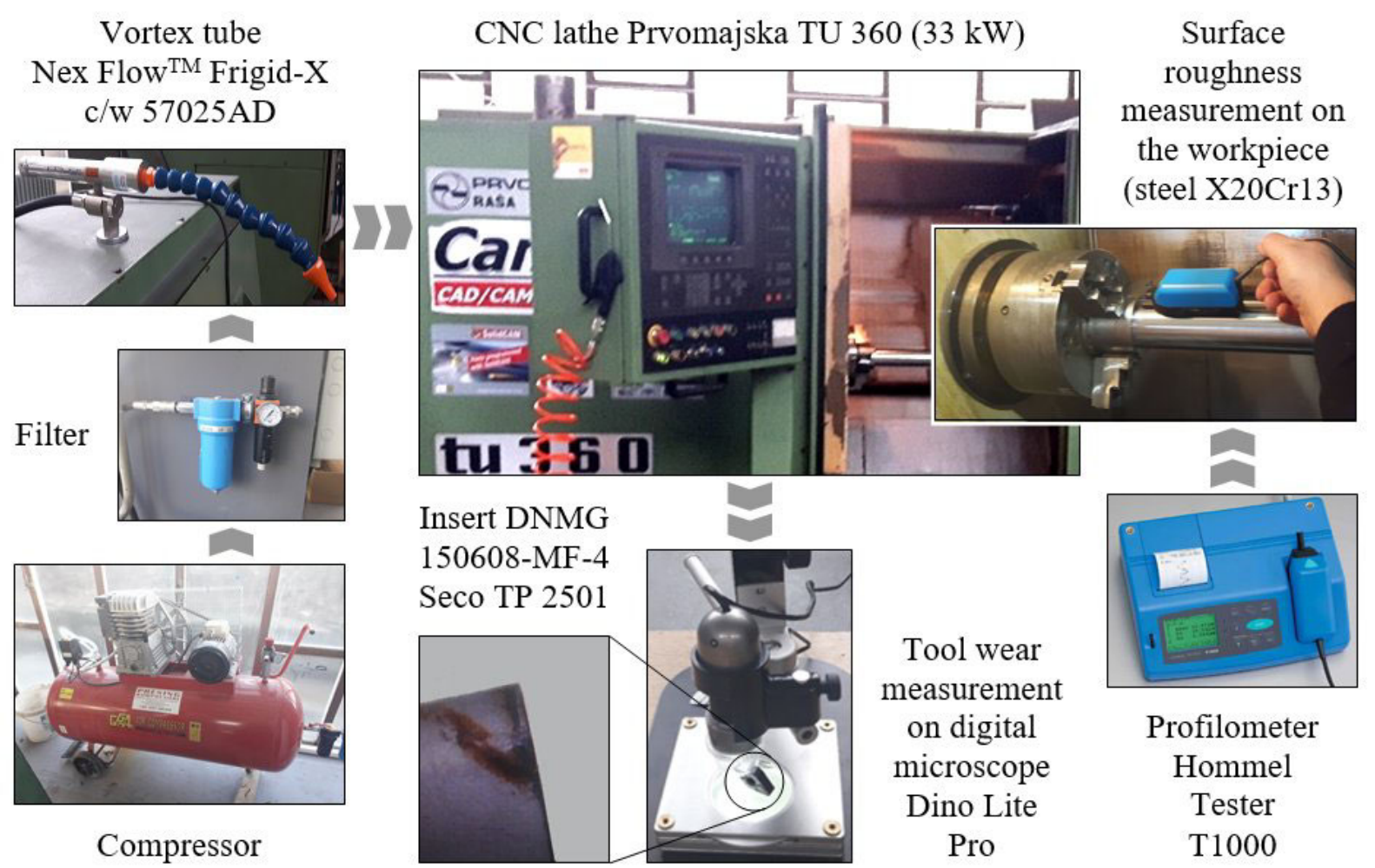

Fig. 2 Experimental configuration for the testing of machinability

\section{Results and discussion}

\subsection{Corrosion resistance analysis}

Corrosion can occur even with dry machining and it is not simply due to the use of water-miscible cutting fluids [20]. From all stainless steels, the martensitic ones are the most sensitive to corrosion.

Corrosion resistance is better with a lower degree of surface roughness. Therefore, it is sensible to determine whether the cooling methods applied significantly affect the $R a$ data shown in Table 1. 
Table 1 Results of machinability testing

\begin{tabular}{cccccccc}
\hline $\begin{array}{c}\text { Exp. } \\
\text { no. }\end{array}$ & $\begin{array}{c}\text { Cutting } \\
\text { speed } \\
v_{c}, \mathrm{~m} / \mathrm{min}\end{array}$ & $\begin{array}{c}\text { Feed per } \\
\text { revolution } \\
f, \mathrm{~mm}\end{array}$ & $\begin{array}{c}\text { Depth of } \\
\text { cut } \\
a_{p}, \mathrm{~mm}\end{array}$ & $\begin{array}{c}\text { Surface roughness } \\
\text { Ra, } \mu \mathrm{m}\end{array}$ & \multicolumn{2}{c}{$\begin{array}{c}\text { Tool life } \\
T, \text { min }\end{array}$} \\
\hline 1 & 170 & 0.2 & 0.3 & 1.530 & 1.249 & 3.28 & 4.92 \\
2 & 270 & 0.2 & 0.3 & 1.979 & 1.151 & 1.48 & 1.21 \\
3 & 170 & 0.4 & 0.3 & 1.873 & 1.857 & 1.42 & 1.33 \\
4 & 270 & 0.4 & 0.3 & 1.973 & 1.822 & 0.80 & 0.28 \\
5 & 170 & 0.2 & 0.5 & 1.184 & 1.407 & 1.68 & 4.06 \\
6 & 270 & 0.2 & 0.5 & 1.032 & 1.291 & 1.35 & 0.95 \\
7 & 170 & 0.4 & 0.5 & 1.978 & 1.931 & 0.84 & 0.45 \\
8 & 270 & 0.4 & 0.5 & 1.895 & 1.911 & 0.40 & 0.14 \\
9 & 220 & 0.3 & 0.4 & 1.706 & 1.670 & 0.96 & 0.63 \\
10 & 220 & 0.3 & 0.4 & 1.621 & 1.616 & 0.83 & 0.49 \\
11 & 220 & 0.3 & 0.4 & 1.533 & 1.675 & 0.95 & 0.81 \\
12 & 220 & 0.3 & 0.4 & 1.645 & 1.576 & 0.94 & 0.84 \\
\hline
\end{tabular}

After testing the equality of variances using the $F$-test, it is possible to use a two-sample $t$-test to determine whether the two sets of data differ significantly. Since $F<F$ Critical onetail and probability $P(F<=f)$ one-tail $>0.05(\alpha$-level), as shown in Table 2 , it is reasonable to conclude that the variances are equal. Table 3 shows that $-t$ Critical two-tail $<t$ Stat $<t$ Critical two-tail and probability $P(T<=t)$ two-tail $>0.5(\alpha$-level); one can see that the means of the measured values of surface roughness parameter $R a$ in the two groups are not significantly different. In conclusion, cooling methods do not significantly affect the machined surface roughness and, hence, the corrosion resistance.

Table 2 The two-sample $F$-test done on the $R a$ data for variances (Excel)

\begin{tabular}{lcc}
\hline & Emulsion & Vortex tube \\
\hline Mean & 1.662417 & 1.596333 \\
Variance & 0.096294 & 0.071849 \\
Observations & 12 & 12 \\
$d f$ & 11 & 11 \\
$F$ & 1.340215 & \\
$P(F<=f)$ one-tail & 0.317792 & \\
$F$ Critical one-tail & 2.817930 & \\
\hline
\end{tabular}

Table 3 The two-sample $t$-test done on the $R a$ data assuming equal variances (Excel)

\begin{tabular}{lcc}
\hline & Emulsion & Vortex tube \\
\hline Mean & 1.662417 & 1.596333 \\
Variance & 0.096294 & 0.071849 \\
Observations & 12 & 12 \\
Pooled Variance & 0.084071 & \\
Hypothesized Mean Difference & 0 & \\
$d f$ & 22 & \\
$t$ Stat & 0.558269 & \\
$P(T<=t)$ two-tail & 0.582299 & \\
$t$ Critical two-tail & 2.073873 & \\
\hline
\end{tabular}


As for the corrosion resistance, the highest possible chromium $(\mathrm{Cr})$ content and the lowest possible carbon (C) content are preferable. The results of SEM/EDS analysis are shown in Figure 3. In the case of the vortex tube cooling, the machined surface had a higher content of chromium and appreciably lower content of carbon. Again, it seems that the cooling by chilled compressed air does not affect adversely the corrosion resistance.

Gravimetric corrosion rates $C R_{G}$ of the tested specimens are given in Table 4. Stainless steels are normally considered resistant to uniform corrosion in a given environment if the corrosion rate does not exceed $0.1 \mathrm{~mm} /$ year [21]. This requirement is met by both specimens; slightly better corrosion resistance of the specimen cooled by emulsion during turning can be attributed to its lower surface roughness.

Table 4 Gravimetric corrosion rates (14 days, $3.5 \% \mathrm{NaCl}$ aqueous solution, $25^{\circ} \mathrm{C}$ )

\begin{tabular}{lcccc}
\hline Specimen & $R a, \mu \mathrm{m}$ & Initial mass $m, \mathrm{~g}$ & $\Delta m, \mathrm{~g}$ & $C R_{G}, \mathrm{~mm} /$ year \\
\hline Emulsion cooled & 1.533 & 4.5307 & 0.0059 & 0.036 \\
Vortex tube cooled & 1.675 & 4.4051 & 0,0078 & 0.048 \\
\hline
\end{tabular}
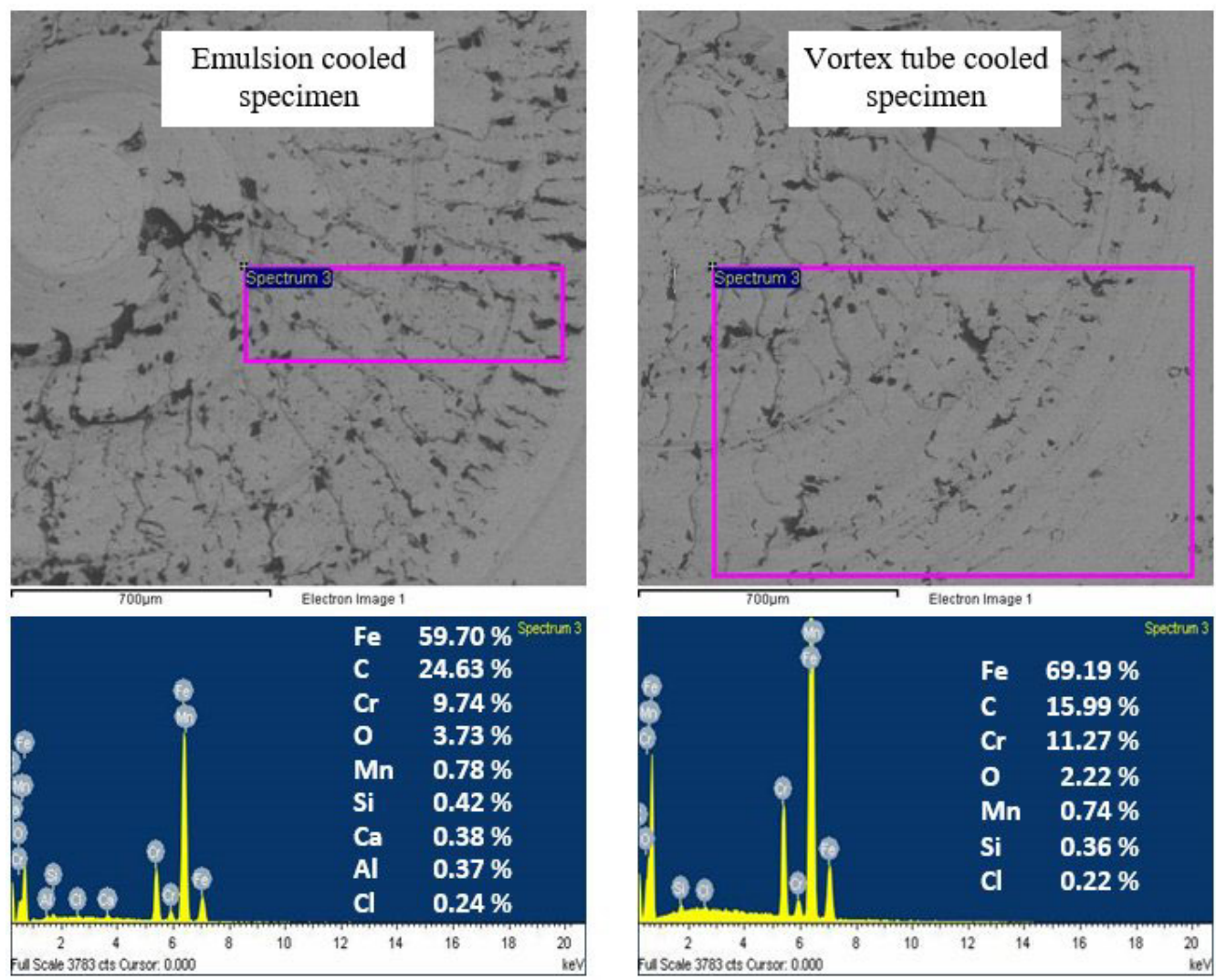

Fig. $3 \mathrm{SEM} / \mathrm{EDS}$ analysis of the emulsion and vortex tube cooled specimens after turning $\left(v_{c}=220 \mathrm{~m} / \mathrm{min}, f=0.3 \mathrm{~mm} /\right.$ revolution and $\left.a_{p}=0.4 \mathrm{~mm}\right)$

\subsection{Cost analysis of the transition to sustainable turning}

In the cost analysis of the transition to sustainable turning, the tool life $T$ is a key factor. Based on the results of multiple linear regression analysis of the tool life shown in Table 1, the following mathematical models were created:

$$
\begin{aligned}
& T_{\text {Emulsion }}=e^{4.512} v_{c}^{-1.28} f^{-1.23} a_{p}^{-0.99} \rightarrow R^{2}=0.936458 \\
& T_{\text {Vortex tube }}=e^{11.96} v_{c}^{-3.02} f^{-2.5} a_{p}^{-1.09} \rightarrow R^{2}=0.958592
\end{aligned}
$$




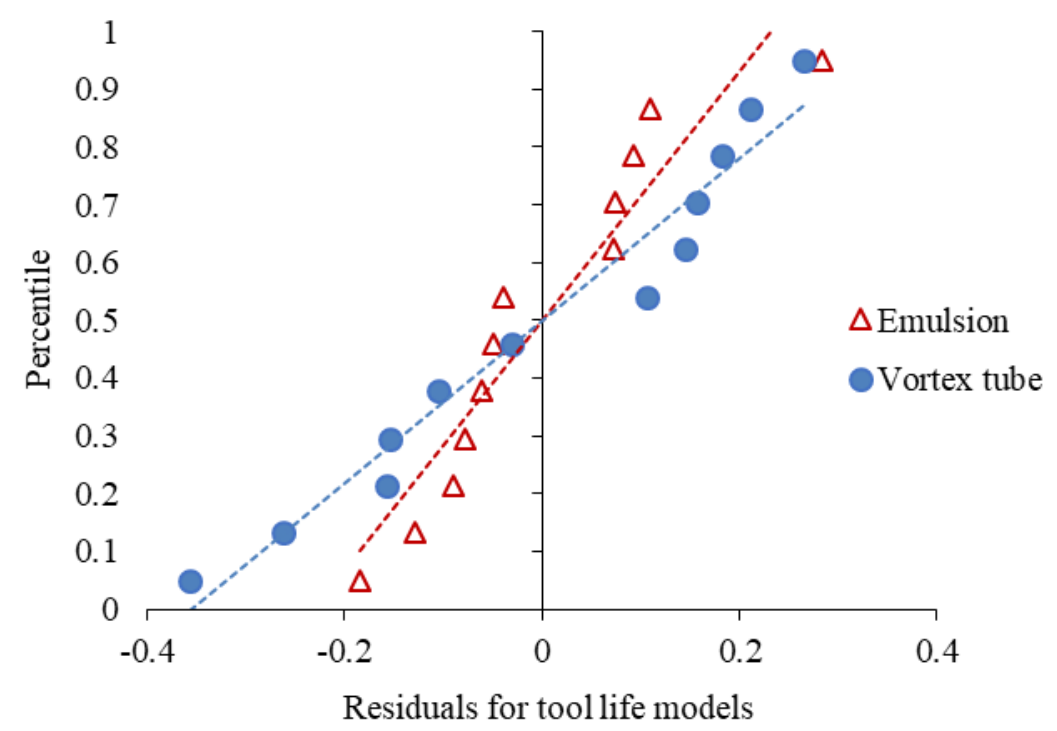

Fig. 4 Normal probability plot of the residuals in the tool life experiments

The $R^{2}$ values (coefficient of determination) are high and close to one, meaning that the models can be successfully applied for predicting the tool life. Also, according to the normal probability plot of the residuals in the tool life experiments shown in Figure 4, errors can be estimated as normally distributed and the proposed models are adequate.

The structure of the unit production cost $C_{1}$ is shown in Table 5. The calculation refers to the turning with $v_{c}=220 \mathrm{~m} / \mathrm{min}, f=0.2 \mathrm{~mm} /$ revolution, and $a_{p}=0.4 \mathrm{~mm}$ for 1968 working hours per year.

The auxiliary-time cost per part $C_{a}$ is proportional to the time spent on the loading and unloading of the workpiece and to the fast positioning and returning of the tool, i.e. the auxiliary time $t_{a}$, while the machining cost per part $C_{m}$ is proportional to the time spent in the feed mode, i.e. the machining time $t_{m}$; the proportionality factor is the hourly rate of machine tool usage $C_{h r}$. The tool changing cost per part $C_{t c}$ can be obtained by multiplying the hourly rate of machine tool usage $C_{h r}$ and the tool changing time per part $t_{c}$. The time $t_{c}$ can be obtained by multiplying the average time required to change a cutting edge $t_{t 1}$ and the number of cutting edges used per part $t_{m} / T$. It should be noted that the reciprocal of the latter, i.e. $T / t_{m}$, represents the number of machined parts per tool life. The tooling cost per part $C_{t p}$ is equal to the purchase price of a cutting insert and a holder per the cutting edge $C_{t 1}$ multiplied by the number of cutting edges used per part $t_{m} / T$. From the perspective of one machine tool, the basic cost of using cooling medium per part $C_{f}$ can be calculated by adding the costs of procurement, distribution, and disposal of the cooling medium, as well as of the cleaning of the workpiece from all traces of emulsion, cleaning of chips by degreasing for the purpose of storing emulsion residues, and preparation of the chips for collection and recycling. The distribution cost refers to the energy cost of a device (pump or compressor) responsible for the circulation of cooling medium. Generally, in the case of emulsion, the disposal price is higher than or equal to the procurement price. The energy cost of a machine tool $C_{e}$ can be calculated by adding the energy cost in the standby mode (changing the workpiece and the cutting edge) and the cost of energy required for machining. 
Table 5 Structure of the unit production cost

\begin{tabular}{lcc}
\hline Category & Emulsion & Vortex tube \\
\hline Hourly rate of machine tool usage $C_{h r}, € /$ hour & 38.74 & 38.74 \\
Purchase price of cutting insert and holder $C_{t 1}, € /$ edge & 2.85 & 2.85 \\
Time required to change a cutting edge $t_{t 1}$, min/edge & 0.50 & 0.50 \\
Tool life $T$, min/edge & 1.64 & 2.00 \\
Auxiliary time $t_{a}$, min/part & 4.60 & 4.60 \\
Machining time $t_{m}$, min/part & 2.67 & 2.67 \\
Tool changing time $t_{c}$, min/part & 0.81 & 0.67 \\
Number of machined parts per tool life $T / t_{m}$, part/edge & 0.61 & 0.75 \\
Auxiliary-time cost $C_{a}, € /$ part & 2.97 & 2.97 \\
Machining cost $C_{m}, € /$ part & 1.73 & 1.73 \\
Tool changing cost $C_{t c}, € /$ part & 0.51 & 0.44 \\
Tooling cost $C_{t p}, € /$ part & 4.67 & 3.80 \\
Cooling medium $\operatorname{cost} C_{f}, € /$ part & 0.10 & 0.02 \\
Machine tool energy cost $C_{e}, € /$ part & 0.01 & 0.01 \\
Material cost $C_{w m}, € /$ part & 65.04 & 65.04 \\
\hline Unit production $\operatorname{cost} C_{1}, € /$ part & 75.03 & 74.01 \\
\hline
\end{tabular}

According to Table 5, the unit production cost in the case of vortex tube cooling in the observed machining conditions is lower by $1.02 € /$ part than in the case of wet machining. The tool life and the cooling medium have the greatest impact on the unit production cost.

The unit production cost is also correlated with the time of changing the worn cutting edge. Considering the investigated cutting parameters, the changing time of a cutting edge contributes greatly to the unit production cost in wet machining. The real period of time required for changing the cutting edge in wet machining is not longer than in the machining using a vortex tube, but the number of changes is larger because of faster cutting edge wear in wet machining. Consequently, the tool cost is higher in wet machining.

Table 6 shows the elements used for determining the contribution of cooling medium to the unit production cost. From the perspective of environmental protection and health of workers, it is desirable to remove completely the oil-based cutting fluids. In addition, the economic benefit is desirable. The observed machine tool consumes 8001 of emulsion per year. Expressed as the procurement and disposal costs, this is equivalent to an amount of $535.90 €$ per year. On the other hand, the capital cost of the investment in cooling with chilled compressed air amounts to $635.64 €$ (vortex tube - $486.45 €$; pressure regulator, filter, manometer, and hose - $149.19 €$; the production facility already owns an air compressor). Therefore, based on the return on investment calculation, the benefit can be obtained in only 14 months. Here, it is necessary to point out 5.67 times higher distribution cost of the compressor in the case of vortex tube cooling than in the case of wet machining, but all in all, the vortex tube cooling is more cost-effective. 
Table 6 Structure of the cooling medium application cost

\begin{tabular}{lcc}
\hline Category & Emulsion & Vortex tube \\
\hline Procurement cost, $€ /$ part & 0.007 & 0.003 \\
Distribution cost, $€ /$ part & 0.003 (pump) & 0.017 (compressor) \\
Disposal cost, $€ /$ part & 0.01 & 0.00 \\
Part cleaning cost, $€ /$ part & 0.06 & 0.00 \\
Chip cleaning cost, $€ /$ part & 0.02 & 0.00 \\
\hline Cooling medium cost $C_{f}, € /$ part & 0.10 & 0.02 \\
\hline
\end{tabular}

The unit production cost can be estimated for different cutting speeds while maintaining the constant feed and depth of cut. Such an evaluation is shown in Figure 5.

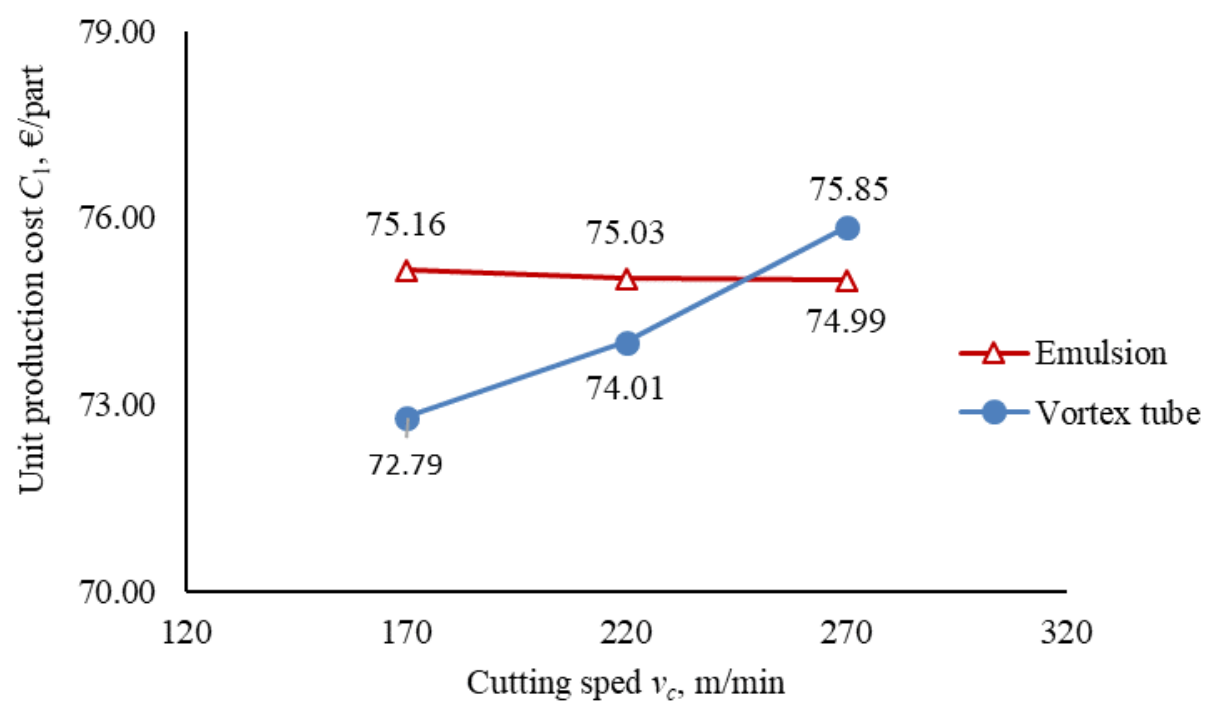

Fig. 5 The dependence of unit production cost on cutting speed $\left(f=0.2 \mathrm{~mm} /\right.$ revolution and $\left.a_{p}=0.4 \mathrm{~mm}\right)$

For the observed case of turning, the vortex tube cooling is more cost-effective up to $v_{c}=248.64 \mathrm{~m} / \mathrm{min}$ than wet machining. This means that above this value of cutting speed, the vortex tube cooling can no longer provide a better tool life compared to the cooling with emulsion because accelerated tool wear occurs, which consequently leads to the tool failure. This indicates that a higher quality of the cutting edge material should be used for the vortex tube cooling in the observed range of cutting speeds compared to the wet turning.

\section{Conclusions}

In the first part of this paper, the ecological, health, and economic aspects of the application of cutting fluids in production are considered. In this regard, cooling by chilled compressed air carried out by means of a vortex tube is presented as a feasible and sustainable alternative cooling technique comparable to the wet machining. The air used as a cooling medium is completely natural and the transition from oil-based cutting fluids to chilled compressed air is a step forward towards sustainable machining, resulting in a significant decrease in the ecological load and in the risk of danger to human health. 
In the second part of the paper, the feasibility of applying a vortex tube for cooling during the turning of martensitic stainless steel X20Cr13 is investigated. It has been determined that there is no significant influence of vortex tube cooling on the corrosion resistance of the machined surface. In addition, cooling with the vortex tube was estimated in terms of unit production cost. It has been proved that the avoidance of emulsion cooling, lower costs attached to waste, and longer tool life reduce the unit production cost in comparison with that in wet machining. This confirms that, besides ecological and health benefits, the vortex tube cooling can obviously offer considerable economic benefits.

\section{Acknowledgement}

This work was supported by the University of Rijeka, Croatia, Grant No. uniri-tehnic-18-293.

\section{REFERENCES}

[1] Mortier, R.M., Fox, M.F., Orszulik, S.T.: Chemistry and Technology of Lubricants (3rd Edition), Springer Science+Business Media B.V., 2010, 435-457.

[2] Brinksmeier, E., Meyer, D., Huesmann-Cordes, A.G., Herrmann, C.: Metalworking fluids - Mechanisms and performance, CIRP Annals - Manufacturing Technology, 64, 2015, 2, 605-628. https://doi.org/10.1016/j.cirp.2015.05.003

[3] Liao, Y. S., Lin, H. M.; Chen, Y. C.: Feasibility study of the minimum quantity lubrication in high-speed end milling of NAK 80 hardened steel by coated carbide tool, International Journal of Machine Tools and Manufacture, 47, 2007, 11, 1667-1676. https://doi.org/10.1016/j.ijmachtools.2007.01.005

[4] Ezugwu, E.O.: Key improvements in the machining of difficult-to-cut aerospace superalloys, International Journal of Machine Tools and Manufacture, 45, 2005, 12-13, 1353-1367. https://doi.org/10.1016/j.ijmachtools.2005.02.003

[5] Boswell, B.: Use of air-cooling and its effectiveness in dry machining processes, PhD Thesis, Curtin University, Australia, 2008.

[6] Weinert, K., Inasaki, I., Sutherland, J.W., Wakabayashi T.: Dry Machining and Minimum Quantity Lubrication, CIRP Annals - Manufacturing Technology, 53, 2004, 2, 511-537. https://doi.org/10.1016/s0007-8506(07)60027-4

[7] Klocke, F.: Manufacturing Processes 1 - Cutting, Translated by Aaron Kuchle, Springer-Verlag, Berlin Heidelberg, 2011.

[8] Pavić, A.: Technology - Machining, Karlovac University of Applied Sciences, Karlovac, 2013. (in Croatian)

[9] Byrne, G., Dornfeld, D., Denkena, B.: Advancing cutting technology, CIRP Annals - Manufacturing Technology, 52, 2003, 2, 483-507. https://doi.org/10.1016/s0007-8506(07)60200-5

[10] 2000/532/EC: Commission Decision of 3 May 2000 replacing Decision 94/3/EC establishing a list of wastes pursuant to Article 1(a) of Council Directive 75/442/EEC on waste and Council Decision 94/904/EC establishing a list of hazardous waste pursuant to Article 1(4) of Council Directive 91/689/EEC on hazardous waste (notified under document number C(2000) 1147) (Text with EEA relevance). https://doi.org/10.5771/9783845271873-920

[11] Directive 2008/98/EC of the European Parliament and of the Council of 19 November 2008 on waste and repealing certain Directives (Text with EEA relevance).

[12] Pusavec, F., Kramar, D., Krajnik, P., Kopac, J.: Transitioning to sustainable production - part II: evaluation of sustainable machining technologies, Journal of Cleaner Production, 18, 2010, 1211-1221. https://doi.org/10.1016/j.jclepro.2010.01.015

[13] Hong, S.Y., Zhao, Z.: Thermal aspects, material considerations and cooling strategies in cryogenic machining, Clean Technologies and Environmental Policy, 1, 1999, 107-116. https://doi.org/10.1007/s100980050016

[14] Celent, L.: Implementation of Compressed Cold Air Using Vortex Tube in Milling Process, PhD Thesis, Faculty of Electrical Engineering, Mechanical Engineering and Naval Architecture, Split, 2014. (in Croatian)

[15] Dixit, U.S., Sarma, D.K., Davim, J.P.: Environmentally friendly machining, Springer, New York, USA, 2012. 
[16] Kostadin, T., Cukor, G.: An overview of the development and use of coolant and lubricant systems in machining. In: Proceedings CIM 2015, Croatian Association of Production Engineering, Zagreb, 153160, 2015.

[17] Ginting, Y.R., Boswell, B., Biswas, W.K., Islam, M.N.: Environmental Generation of Cold Air for Machining, Procedia CIRP, 40, 2016, 648-652. https://doi.org/10.1016/j.procir.2016.01.149

[18] ISO 3685: Tool-life testing with single-point turning tools, International Organization for Standardization, Geneva, 1993.

[19] ASTM G1-03: Standard practice for preparing, cleaning, and evaluating corrosion test specimens, ASTM International, West Conshohocken, PA, 2011.

[20] Foltz, G.: Corrosion and metalworking fluids, 2003.

[21] Handbook of stainless steel, Outokumpu Oyj, Espoo, Finland, 2013.

Submitted: $\quad 20.02 .2019$

Accepted: $\quad$ 13.3.2019
Prof. Goran Cukor

goranc@riteh.hr

Graciela Šterpin-Valić

University of Rijeka,

Faculty of Engineering,

Vukovarska 58,

Rijeka, Croatia

Tihana Kostadin

Karlovac University of Applied Sciences, Ivana Meštrovića 10,

Karlovac, Croatia

Marko Fabić

Clinical Hospital Centre Rijeka,

Krešimirova 42,

Rijeka Croatia 